\title{
Maturação da maçã 'Fuji’ em função do atraso na colheita e da aplicação pré-colheita de aminoetoxivinilglicina
}

\author{
Maturation of 'Fuji' apple in function of delay harvest and preharvest \\ aminoethoxyvynilglycine treatment
}

\section{Auri Brackmann $^{1}$ Cristiano André Steffens ${ }^{2}$ Ricardo Fabiano Hettwer Giehl ${ }^{3}$}

\section{RESUMO}

Este trabalho foi conduzido com o objetivo de avaliar o efeito do atraso na colheita e da aplicação pré-colheita de aminoetoxivinilglicina sobre a queda de frutos e maturação da maçã 'Fuji'. Os tratamentos usados foram três doses de aminoetoxivinilglicina $\left(0,90\right.$ e $\left.125 \mathrm{~g} . \mathrm{ha}^{-1}\right)$ combinadas com três épocas de colheita (195, 204 e 225 dias após o pleno florescimento). Não houve interação entre os fatores dose de aminoetoxivinilglicina e época de colheita. A aplicação de aminoetoxivinilglicina na cultivar Fuji manteve a cor da epiderme mais verde, reduziu a respiração, a produção de etileno e a incidência de pingo-de-mel. O atraso na colheita proporcionou frutos com menor respiração, cor vermelha mais intensa e sólidos solúveis totais mais elevados. Além disso, o retardamento na colheita causou maior queda de frutos, amarelecimento da epiderme, maior incidência de pingo-de-mel, índice iodo-amido mais elevado, alta produção de etileno, menor firmeza de polpa e menor acidez titulável.

Palavras-chave: Malus domestica Borkh, etileno, distúrbios fisiológicos.

\section{ABSTRACT}

This research was carried out with the aim evaluating the effect of preharvest treatment with aminoethoxyvynilglycine and harvest delay on fruit drop and maturation of apple cultivar Fuji. The treatments were three doses of aminoethoxyvynilglycine $\left(0,90\right.$ e $\left.125 \mathrm{~g}^{-\mathrm{ha}^{-1}}\right)$ combined with three harvest dates (195, 204, 225 days after full bloom). No interaction between doses of aminoethoxyvynilglycine and harvest date was found. The application of aminoethoxyvynilglycine in the apple cultivar Fuji maintained greener ground skin color, reduced ethylene production, respiration rate and watercore incidence. Delaying fruit harvest showed lower respiration, better red color and higher total solids soluble. In addition to this, late harvest caused higher fruit drop, skin yellowing, high watercore incidence, high starch index, high ethylene production, low flesh firmness and low titratable acidity.

Key words: Malus domestica Borkh, ethylene, physiological disorders.

\section{INTRODUÇÃO}

A maçã (Malus domestica Borkh) 'Fuji' é a segunda cultivar em importância no Brasil, sendo a incidência de pingo-de-mel um dos grandes problemas desta maçã. O pingo-de-mel é um distúrbio fisiológico causado pela presença de sorbitol e sacarose, que se acumulam nos espaços intercelulares das maçãs, não sendo absorvidos pelas células (BRACKMANN et al., 2002a). Estes mesmos autores citam que frutos colhidos tardiamente apresentam maior incidência de pingo-de-mel e com maior severidade. A presença de pingo-de-mel pode resultar em elevados índices de degenerescência da polpa durante o armazenamento em atmosfera controlada, conforme observado por BRACKMANN et al. (2002b) em maçãs 'Braeburn'.

$\mathrm{O}$ atraso na colheita, além de aumentar a incidência de distúrbios fisiológicos, causa perdas devido à queda pré-colheita de frutos, redução da firmeza de polpa, menor conteúdo de ácidos orgânicos

\footnotetext{
${ }^{1}$ Engenheiro Agrônomo, Doutor departamento de Fitotecnia, Centro de Ciências Rurais, Universidade Federal de Santa Maria (UFSM), 97105-900, Santa Maria, RS. E-Mail:brackmann@ccr.ufsm.br

${ }^{2}$ Engenheiro Agrônomo, Acadêmico do Programa de Pós-graduação em Agronomia, UFSM, Bolsista CAPES. Departamento de Fitotecnia, Centro de Ciências Rurais (CCR), UFSM, 97105-900, Santa Maria, RS. E-mail: cristianosteffens@bol.com.br

${ }^{3}$ Acadêmico de Agronomia da UFSM, Bolsista FAPERGS. Departamento de Fitotecnia, CCR, UFSM. E-mail: hetgiehl@yahoo.com.br
} 
e de amido (BOWEN \& WATKINS, 1997; PLOTTO et al., 1997; WARD et al., 1999; WANG \& DILLEY, 2001), porém proporciona frutos com cor da epiderme mais vermelha (WANG \& DILLEY, 2001; AWAD \& de JAGER, 2002), fator responsável pelo atraso na colheita.

A aplicação de aminoetoxivinilglicina em maçã 'Gala' reduz a queda de frutos e retarda o processo de maturação (BANGERTH, 1978; BRACKMANN \& WACLAWOVSKY, 2001; STEFFENS, 2003), além de inibir a síntese de $\alpha$ farnesene, composto envolvido no surgimento da escaldadura superficial em maçãs e pêras (MIR et al., 1999; JU \& CURRY, 2000; JU \& BRAMLAGE, 2001). O efeito do aminoetoxivinilglicina sobre os diferentes eventos fisiológicos associados ao processo de maturação e amadurecimento de frutos ocorre através da inibição da síntese de etileno. Tem sido verificado, em alguns trabalhos, que o aminoetoxivinilglicina reduz a incidência de pingode-mel em maçãs (CLARKE et al., 1996; BYERS, 1997). Entretanto, o aminoetoxivinilglicina pode afetar negativamente a qualidade dos frutos por reduzir a cor vermelha (WANG \& DILLEY, 2001; AWAD \& de JAGER, 2002; STEFFENS, 2003) e a produção de aroma (FAN et al., 1998; MIR et al., 1999). No entanto, são poucos os trabalhos existentes avaliando o efeito do aminoetoxivinilglicina sobre a qualidade da maçã 'Fuji', especialmente sobre a incidência do distúrbio fisiológico pingo-de-mel.

Desta forma, o objetivo deste trabalho foi avaliar o efeito da aplicação pré-colheita de aminoetoxivinilglicina e do atraso na colheita sobre a queda de frutos, maturação e qualidade da maçã cultivar Fuji, principalmente quanto à incidência de pingo-de-mel.

\section{MATERIAL E MÉTODOS}

O experimento foi conduzido no ano agrícola de 2001/2002 com frutos da cultivar Fuji, enxertadas sobre porta-enxerto EM-7, em um pomar comercial localizado no município de Vacaria, RS. As plantas utilizadas possuíam 12 anos de idade, sendo cultivadas em um solo seco de textura argilosa, com $4 \%$ de matéria orgânica e $\mathrm{pH}$ 6,5. O espaçamento entre plantas foi de $2,0 \mathrm{~m} \times 4,5 \mathrm{~m}$ e a data do pleno florescimento ocorreu no dia 07/10/2001.

Os tratamentos constituíram-se da pulverização pré-colheita de três doses de aminoetoxivinilglicina $\left(0,90\right.$ e $\left.125 \mathrm{~g} \cdot \mathrm{ha}^{-1}\right)$ sobre as plantas, em combinação com três épocas de colheita (195, 204, 225 dias após o pleno florescimento). O delineamento experimental utilizado foi o blocos ao acaso com quatro repetições, sendo a unidade experimental composta de 10 plantas para a análise da queda pré-colheita de frutos e 10 frutos para a análise dos demais parâmetros.

A fonte de aminoetoxivinilglicina foi $o$ produto ReTain, com $15 \%$ de ingrediente ativo. No momento da aplicação do aminoetoxivinilglicina, a temperatura média foi de $29,5^{\circ} \mathrm{C}$ e umidade relativa do ar de $70 \%$. A primeira colheita foi realizada sete dias após o início da colheita comercial, a fim de proporcionar um maior desenvolvimento de pingo-demel.

A aplicação do aminoetoxivinilglicina foi realizada, mecanicamente, com um turboatomizador de capacidade de $2000 \mathrm{~L}$ acoplado a um trator, 35 dias antes da primeira colheita (28 dias antes do início da colheita comercial). O volume da calda utilizado foi equivalente a 1000L.ha' ${ }^{-1}$. Na aplicação do aminoetoxivinilglicina houve molhamento completo de folhas e frutos, sem escorrimento. $\mathrm{O}$ espalhante adesivo utilizado juntamente com o aminoetoxivinilglicina foi o Silwet L77 (grupo organosilicone), na dose de $0,05 \% \mathrm{v} / \mathrm{v}$.

Os parâmetros avaliados foram: a) queda de frutos: quantificada através da contagem dos frutos caídos, determinando sua proporção em relação ao número total de frutos das plantas; b) índice iodoamido: foi determinado pela reação do amido com uma solução com $12 \mathrm{~g}$ de iodo metálico e $24 \mathrm{~g}$ de iodeto de potássio em $1 \mathrm{~L}$ de água destilada. Após um corte no equador dos frutos, foi aplicada a solução de iodo na superfície cortada da metade peduncular do fruto, a qual foi comparada (reação do iodo com o amido) com a tabela de fotografias desenvolvida por STREIF (1984), onde o índice 01 indica o teor máximo de amido, e o índice 10 representa o amido totalmente hidrolisado; c) produção de etileno: uma sub-amostra de cada amostra foi acondicionada em recipientes de 5 litros que, posteriormente, foram fechados hermeticamente durante aproximadamente 2 horas, a $20^{\circ} \mathrm{C}$. Após este período, utilizando uma seringa plástica de $1 \mathrm{~mL}$, foram coletadas duas amostras da atmosfera do espaço livre destes recipientes e injetadas em um cromatógrafo a gás marca Varian, modelo $3100 X$, equipado com coluna Porapak N e operando com as temperaturas de $90^{\circ} \mathrm{C}, 140^{\circ} \mathrm{C}$ e $200^{\circ} \mathrm{C}$ para a coluna, injetor e detector, respectivamente. Através da concentração de etileno, do peso dos frutos, do volume do espaço livre no recipiente e do tempo de fechamento, foi calculada a produção de etileno em $\mu \mathrm{L} \mathrm{C}_{2} \mathrm{H}_{4} \cdot \mathrm{kg}^{-1} \cdot \mathrm{h}^{-1}$; d) respiração: expressa através da produção de $\mathrm{CO}_{2}$. $\mathrm{O}$ ar do mesmo recipiente que foi 
utilizado para determinação da produção de etileno, foi circulado através de um analisador eletrônico de $\mathrm{CO}_{2}$, marca Agri-datalog, e através da concentração de $\mathrm{CO}_{2}$ do espaço livre do recipiente juntamente com a determinação do volume do espaço livre, do peso dos frutos e do tempo de fechamento, foi calculada a respiração em $\mathrm{mL} \mathrm{CO}_{2} \cdot \mathrm{kg}^{-1} \cdot \mathrm{h}^{-1}$; e) firmeza de polpa: determinada na região equatorial dos frutos, em dois lados opostos, através da remoção de uma pequena porção da epiderme e com auxílio de um penetrômetro equipado com ponteira de $11 \mathrm{~mm}$ de diâmetro; f) acidez titulável: determinada em uma amostra de $10 \mathrm{~mL}$ de suco dos frutos, previamente extraído de fatias transversais retiradas da região equatorial das maçãs e trituradas em uma centrífuga elétrica. Esta amostra foi diluída em $100 \mathrm{~mL}$ de água destilada e titulada com uma solução de hidróxido de sódio $0,1 \mathrm{~N}$ até $\mathrm{pH} 8,1$; g) sólidos solúveis totais: foram determinados por refratometria, utilizando-se o suco extraído conforme descrito no item $\mathrm{f}$, com correção do efeito da temperatura $\left.\left(20^{\circ} \mathrm{C}\right) ; \mathrm{h}\right)$ cor de fundo da epiderme: determinada com um colorímetro eletrônico, marca Minolta, pelo sistema de cores CIE L*a*b, onde o L* representa a claridade, $\mathrm{a}^{*}$ indica a variação da cor vermelha ao verde $\mathrm{e} \mathrm{b}^{*}$ a variação da cor amarela ao azul. Os resultados foram expressos pelo somatório dos valores de $a^{*}$ e b*. Assim, quanto maior o valor desta soma, mais amarelo é o fruto; i) cor vermelha da epiderme: foi determinada através de uma escala com índices de 1 a 4, onde o índice 1 indica uma superfície pigmentada de vermelho equivalente de 0 a $25 \%$ da área total da epiderme, o índice 2 de 25 a 50\%, o índice 3 de 50 a $75 \%$ e o índice de 4 de 75 a $100 \%$ da área total da epiderme; e j) incidência de pingo-de-mel: foi avaliado através da visualização da polpa e comparação desta com a escala elaborada por BOWEN \& WATKINS (1997).

Após a coleta, os dados foram tabulados e submetidos à análise da variância, sendo as médias comparadas pelo teste de Duncan a 5\%. Os dados expressos em porcentagem foram transformados pela fórmula arcsen $\sqrt{\mathrm{x} / 100}$, antes da análise da variância.

\section{RESULTADOS E DISCUSSÃO}

Os resultados da análise da variância não apresentaram significância para a interação entre os fatores doses de aminoetoxivinilglicina e época de colheita em todos os parâmetros avaliados (dados não apresentados).

A aplicação pré-colheita de aminoetoxivinilglicina não apresentou efeito sobre a firmeza de polpa, acidez titulável, sólidos solúveis totais e índice iodo-amido (Tabela 1). Também AUTIO \& BRAMLAGE (1982), trabalhando com a cultivar Puritan, e MIR et al. (1999), com a cultivar Jonagold, não verificaram efeito da aplicação pré-colheita com aminoetoxivinilglicina sobre estes parâmetros. Entretanto, diversos autores verificaram maior firmeza de polpa, acidez titulável e índice de iodo-amido nas cultivares King of the Pippin, Golden Delicious e Gala tratadas com aminoetoxivinilglicina (BANGERTH, 1978; BRACKMANN \& WACLAWOVSKY, 2001; WANG \& DILLEY, 2001). Provavelmente, o aminoetoxivinilglicina não apresentou efeito sobre estes parâmetros devido à pequena redução na produção de etileno e pelo fato de a maçã 'Fuji' ser menos sensível ao etileno do que outras cultivares de maçã, como a 'Gala' por exemplo.

Tabela 1 - Efeito da dose de aminoetoxivinilglicina aplicada em pré-colheita sobre a maturação da maçã 'Fuji', um dia após a colheita. Santa Maria, 2002.

\begin{tabular}{|c|c|c|c|c|}
\hline \multirow{2}{*}{ Características avaliadas } & \multicolumn{3}{|c|}{ Doses de aminoetoxivinilglicina $\left(\mathrm{gha}^{-1}\right)$} & \multirow{2}{*}{$\mathrm{CV}(\%)$} \\
\hline & 0 & 90 & 125 & \\
\hline Firmeza de polpa $(\mathrm{N})$ & $63,6 a^{*}$ & $61,5 \mathrm{a}$ & $63,1 \mathrm{a}$ & 4,19 \\
\hline Acidez titulável $\left(\mathrm{cmolL}^{-1}\right)$ & $4,21 \mathrm{a}$ & $4,45 \mathrm{a}$ & $3,82 \mathrm{a}$ & 9,30 \\
\hline SST ( ${ }^{\circ}$ Brix $)$ & $14,9 \mathrm{a}$ & $14,6 \mathrm{a}$ & $14,3 \mathrm{a}$ & 2,56 \\
\hline Índice iodo-amido (1-10) & $8,47 \mathrm{a}$ & $8,52 \mathrm{a}$ & $8,54 \mathrm{a}$ & 4,54 \\
\hline Cor de fundo $\left(a^{*}+b^{*}\right)$ & $39,7 \mathrm{a}$ & $40,1 \mathrm{a}$ & $36,3 b$ & 6,35 \\
\hline Cor vermelha (1-4) & $2,60 \mathrm{a}$ & $2,41 \mathrm{a}$ & $2,55 \mathrm{a}$ & 8,43 \\
\hline Pingo de mel (0-5) & $0,64 \mathrm{a}$ & $0,47 \mathrm{~b}$ & $0,31 \mathrm{c}$ & 41,07 \\
\hline $\mathrm{C}_{2} \mathrm{H}_{4}\left(\mu \mathrm{Lkg}^{-1} \mathrm{~h}^{-1}\right)$ & $0,25 \mathrm{a}$ & $0,21 \mathrm{ab}$ & $0,18 b$ & 30,48 \\
\hline Respiração $\left(\mathrm{mL} \mathrm{CO}_{2} \mathrm{~kg}^{-1} \mathrm{~h}^{-1}\right)$ & $5,30 \mathrm{a}$ & $4,64 b$ & $4,05 \mathrm{c}$ & 19,90 \\
\hline Queda de frutos (\%) & $7,30 \mathrm{a}$ & $7,45 \mathrm{a}$ & $7,09 \mathrm{a}$ & 6,86 \\
\hline
\end{tabular}

* Médias não seguidas pela mesma letra, na horizontal, diferem pelo teste de Duncan, em nível de 5\% de probabilidade de erro. 
Para a cor vermelha da epiderme também não foi verificado efeito da aplicação de aminoetoxivinilglicina (Tabela 1), confirmando os resultados obtidos por STEFFENS (2003) na maçã 'Fuji'. Porém, WANG \& DILLEY (2001) verificaram redução da cor vermelha nos frutos das cultivares Gala e Jonagold tratadas com aminoetoxivinilglicina. AWAD \& de JAGER (2002) também verificaram que a aplicação de aminoetoxivinilglicina reduziu a cor vermelha de maçãs 'Jonagold', consequiência de uma diminuição significativa na produção de antocianinas, e afirmaram que as antocianinas respondem mais rapidamente a tratamentos promotores e inibidores de etileno, do que outros fenômenos relacionados ao amadurecimento. Estes autores ainda sugeriram que o aminoetoxivinilglicina, pela inibição da síntese de etileno, pode suprimir a expressão dos genes relacionados à biossíntese de antocianinas. No momento em que o etileno endógeno atinge um nível crítico, ele ativa os genes envolvidos na biossíntese de antocianinas. De acordo com MURPHEY \& DILLEY (1988), o aumento da biossíntese de antocianinas pode requerer somente uma breve exposição ao etileno, a qual pode ser insuficiente para afetar outras características do amadurecimento. No presente trabalho, verificou-se uma pequena redução na síntese de etileno pelo aminoetoxivinilglicina (Tabela 1), o que pode ter sido insuficiente para prejudicar o desenvolvimento da cor vermelha dos frutos.

A aplicação de aminoetoxivinilglicina não teve efeito sobre a queda de frutos (Tabela 1), concordando com STEFFENS (2003). Entretanto, nas cultivares Gala, King of the Pippin, Golden Delicious e Redchief Delicious, a pulverização de aminoetoxivinilglicina sobre as plantas reduziu a queda pré-colheita de frutos (BANGERTH, 1978; WARD et al., 1999; STEFFENS, 2003).

A cor de fundo da epiderme apresentou-se mais verde com a dose de $125 \mathrm{~g} \cdot \mathrm{ha}^{-1}$ de aminoetoxivinilglicina (Tabela 1), o que também foi verificado nas cultivares Gala (BRACKMANN \& WACLAWOVSKY, 2001; STEFFENS, 2003), King of the Pippin, Golden Delicious (BANGERTH, 1978) e Jonagold (AWAD \& de JAGER, 2002).

A incidência de pingo-de-mel foi reduzida com a aplicação de aminoetoxivinilglicina, principalmente com a dose de $125 \mathrm{gha}^{-1}$ (Tabela 1). Normalmente, a ocorrência deste distúrbio fisiológico está relacionada ao tamanho do fruto, ao atraso da colheita, aos teores de cálcio na polpa e à temperatura durante o desenvolvimento do fruto, entretanto, o etileno parece ter alguma relação, direta ou indireta, com a sua ocorrência. De acordo com BRACKMANN et al. (2002a), maçãs afetadas por pingo-de-mel apresentam problemas no armazenamento em atmosfera controlada, devido aos maiores índices de degenerescência da polpa. Desta forma, a aplicação pré-colheita de aminoetoxivinilglicina pode ser uma alternativa para evitar a ocorrência de degenerescência da polpa induzida pelo pingo-de-mel, durante o armazenamento da maçã 'Fuji' em atmosfera controlada.

A respiração e a produção de etileno foram levemente reduzidas pela aplicação pré-colheita de aminoetoxivinilglicina (Tabela 1), o que também foi observado nas cultivares King of the Pippin, Golden Delicious (BANGERTH, 1978), Super Red Delicous (FAN et al., 1998), Jonagold (MIR et al., 1999), Gala (BRACKMANN \& WACLAWOVSKY, 2001), Delicious e Granny Smith (JU \& CURRI, 2000; JU \& BRAMLAGE, 2001). Esta redução na produção de etileno é devido ao fato do aminoetoxivinilglicina inibir competitivamente e reversivelmente a enzima ACCsintase, que cataliza a conversão de Sadenosilmetionina para 1-amino-ciclo-propano-1carboxílico (AUTIO \& BRAMLAGE, 1982). Podese verificar que o comportamento da produção de $\mathrm{CO}_{2}$, em função das doses de aminoetoxivinilglicina, foi semelhante à produção de etileno (Tabela 1). Isto evidencia que a redução na respiração dos frutos está diretamente relacionada à redução na produção do etileno.

De acordo com os resultados obtidos neste experimento e com os de outros trabalhos, pode-se verificar uma resposta diferenciada entre cultivares de maçã à aplicação pré-colheita de aminoetoxivinilglicina. De acordo com AUTIO \& BRAMLAGE (1982), a magnitude do efeito do aminoetoxivinilglicina varia em função da cultivar em estudo e da concentração utilizada. O baixo efeito do aminoetoxivinilglicina sobre alguns parâmetros e a ausência de efeito sobre a maioria dos parâmetros analisados, possivelmente esteja relacionado à baixa produção de etileno da cultivar Fuji, conforme verificado neste trabalho (Tabela 1) e por SAQUET \& STREIF (2000).

$\mathrm{O}$ atraso na colheita aumentou a queda de frutos e proporcionou frutos com maior cor de cobertura (cor vermelha), maior teor de sólidos solúveis totais, cor de fundo da epiderme mais amarela, maior incidência de pingo-de-mel e produção de etileno e menor firmeza de polpa, acidez titulável e teor de amido (Tabela 2). Estes resultados são um comportamento normal devido ao avanço da maturação, conforme já observado em diversos outros trabalhos (BOWEN \& WATKINS, 1997; PLOTTO et 
Tabela 2 - Efeito da data de colheita sobre a maturação da maçã 'Fuji', um dia após a colheita. Santa Maria, 2002.

\begin{tabular}{|c|c|c|c|c|}
\hline & \multicolumn{3}{|c|}{ Colheita (DAPF)* } & \multirow{2}{*}{$\mathrm{CV}(\%)$} \\
\hline & 195 & 204 & 225 & \\
\hline Firmeza de polpa $(\mathrm{N})$ & $69,1 a^{* *}$ & $61,8 b$ & $57,3 \mathrm{c}$ & 4,19 \\
\hline Acidez titulável $\left(\mathrm{cmolL}^{-1}\right)$ & $4,48 \mathrm{a}$ & $4,26 \mathrm{a}$ & $3,74 b$ & 9,30 \\
\hline SST $\left({ }^{\circ}\right.$ Brix $)$ & $14,4 \mathrm{~b}$ & $14,6 a b$ & $14,8 \mathrm{a}$ & 2,56 \\
\hline Índice iodo-amido (1-10) & $7,93 b$ & $8,06 b$ & $9,54 \mathrm{a}$ & 4,54 \\
\hline Cor de fundo $\left(a^{*}+b^{*}\right)$ & $35,0 \mathrm{~b}$ & $36,7 b$ & $44,4 \mathrm{a}$ & 6,35 \\
\hline Cor vermelha (1-4) & $2,28 \mathrm{c}$ & $2,51 \mathrm{~b}$ & $2,78 \mathrm{a}$ & 8,43 \\
\hline Pingo de mel (0-5) & $0,02 \mathrm{c}$ & $0,54 \mathrm{~b}$ & $0,86 \mathrm{a}$ & 41,07 \\
\hline $\mathrm{C}_{2} \mathrm{H}_{4}\left(\mu \mathrm{Lkg}^{-1} \mathrm{~h}^{-1}\right)$ & $0,12 b$ & $0,24 \mathrm{a}$ & $0,29 \mathrm{a}$ & 8,43 \\
\hline Respiração $\left(\mathrm{mL} \mathrm{CO}_{2} \mathrm{~kg}^{-1} \mathrm{~h}^{-1}\right)$ & $6,02 \mathrm{a}$ & $4,66 \mathrm{~b}$ & $3,32 \mathrm{c}$ & 19,90 \\
\hline Queda de frutos $(\%)$ & $2,62 c$ & $6,34 b$ & $12,88 \mathrm{a}$ & 6,86 \\
\hline
\end{tabular}

*DAPF - Dias após o pleno florescimento.

** Médias não seguidas pela mesma letra, na horizontal, diferem pelo teste de Duncan, em nível de 5\% de probabilidade de erro.

al., 1997, WARD et al., 1999; WANG \& DILLEY, 2001).

$\mathrm{O}$ aumento na incidência e severidade de pingo-de-mel coincide com o aumento dos sólidos solúveis totais, com a produção de etileno e com o decréscimo da firmeza de polpa (BOWEN \& WATKINS, 1997), sendo que este mesmo comportamento foi observado no presente trabalho (Tabela 2).

A respiração dos frutos, surpreendentemente, reduziu com o atraso na colheita (Tabela 2). Resultado semelhante foi observado em outro trabalho com a cultivar Fuji (STEFFENS, 2003). Este comportamento é observado em frutos após terem atingido o pico climatérico da respiração, quando então ocorre um decréscimo até a fase de senescência.

\section{CONCLUSÃO}

A aplicação pré-colheita de aminoetoxivinilglicina não controla a queda de frutos, não retarda a maturação e também não afeta a coloração vermelha da maçã 'Fuji', porém reduz em $50 \%$ a incidência de pingo-de-mel. $\mathrm{O}$ atraso na colheita reduz a qualidade dos frutos, podendo causar problemas durante o armazenamento.

\section{REFERÊNCIAS BIBLIOGRÁFICAS}

AUTIO, W.R.; BRAMLAGE, W.J. Effects of AVG on maturation, ripening and storage of apples. Journal of the American Society of Horticultural Science, Alexandria, v.107, n.6, p.1074-1077, 1982 .
AWAD, M.A.; de JAGER, A. Formation of flavonoids, especially anthocyanin and chlorogenic acid in 'Jonagold' apple skin: influences of growth regulators and fruit maturity. Scientia Horticulturae, Amsterdam, n.93, p.257-266, 2002.

BANGERTH, F. The effect of a substituted amino acid on ethylene biosynthesis, respiration, ripening and preharvest drop of apple fruits. Journal of the American Society of Horticultural Science, Alexandria, v.103, n.3, p.401-404, 1978.

BOWEN, J.H.; WATKINS, C.B. Fruit maturity, carbohydrate and mineral content relationships with watercore in 'Fuji' apples. Postharvest Biology and Technology, Amsterdam, v.11, p.3138,1997

BRACKMANN, A. et al. Avaliação da temperatura e condições de atmosfera controlada em frutos com incidência de pingo de mel. Revista Brasileira de Agrociência, Pelotas, v.8, n.1, p.37452, 2002a.

BRACKMANN, A.; STEFFENS, C.A., WACLAWOVSKY, A.J. Efeito da data de colheita e do armazenamento em atmosfera controlada na qualidade da maçã cv. Braeburn. Pesquisa Agropecuária Brasileira, Brasília, v.37, n.03, p.371-377, 2002b.

BRACKMANN, A.; WACLAWOVSKY, A.J. Responses of 'Gala' apples to preharvest treatment with AVG and low ethylene CA storage. Acta Horticulturae, Leuven, n.553, p.155-157, 2001.

BYERS, R.E. Peach and nectarine fruit softening following aminoethoxyvinylglycine sprays and dips. HortScience, Alexandria, v.32, n.1, p.86-88, 1997.

CLARKE, G.G. et al. ABG-3168: a new, naturally-occurring plant growth regulator for the apple industry. New England Fruit Meetings, n.102, p.79-84, 1996.

FAN, X.; MATTHEIS, J.P.; BUCHANAN, D. Continuous requirement of ethylene for apple fruit volatile synthesis. Journal of Agricultural and Food Chemistry, Washington, v.46, n.5, p.1959-1963, 1998. 
JU, Z.; BRAMLAGE, W.J. Developmental changes of cuticular constituents and their association with ethylene during fruit ripening in 'Delicious' apples. Postharvest Biology and Technology, Amsterdam, v.21, p.257-263, 2001

JU, Z.; CURRY, E.A. Evidence that a-farnesene biosynthesis during fruit ripening is mediated by ethylene regulated gene expression in apples. Postharvest Biology and Technology, Amsterdam, v.19, p.9-16, 2000.

MIR, N.A. et al. Relationship between ethylene response manipulation and volatile production in Jonagold variety apples. Journal of Agricultural and Food Chemistry, Washington, v.47, n.7, p.2653-2659, 1999.

MURPHEY, A.S.; DILLEY, D.R. Anthocyanin biosynthesis and maturity of McIntosh apples as influenced by ethylene-releasing compounds. Journal of the American Society of Horticultural Science, Alexandria, v.113, n.2, p.718-723, 1988.

PLOTTO, A.; AZARENKO, A.N. Eating quality of 'Gala' and 'Fuji' apples from multiple harvests and storage durations. HortScience, Alexandria, v.32, n.5, p.903-908, 1997.
SAQUET, A.A.; STREIF, J. Investigations on the respiration and the ethylene production of some new apple cultivars. Erwerbsobstbau, Berlin, v.42, n.4, p.109-112, 2000 .

STEFFENS, C.A. Maturação e qualidade pós-colheita de maçãs, 'Gala' e 'Fuji', com aplicação pré-colheita de aminoetoxivinilglicina e ethephon. 2003. 88f. Dissertação (Mestrado em Agronomia) - Universidade Federal de Santa Maria.

STREIF, J. Jod-Stärke-Test zur Beurteilung der Fruchtreife bei Äpfeln. Obst und Garten, Stuttgart, n.8, p.12, 1984.

WANG, Z.; DILLEY, D.R. Aminoethoxyvinylglycine, combined with ethephon, can enhance red color development without overripening apples. HortScience, Alexandria, v.36, n.2, p.328-331, 2001 .

WARD, D.L.et al. Cutting apple fruits induces cellulase activity in the abscission zone. HortScience, Alexandria, v.34, n.4, p.601603, 1999. 